\title{
Sirt1 inhibition promotes in vivo arterial thrombosis and tissue factor expression in stimulated cells
}

\author{
Alexander Breitenstein 1,2,3†, Sokrates Stein ${ }^{1,2 \dagger}$, Erik W. Holy 1,2,3, Giovanni G. Camici ${ }^{1,2}$, \\ Christine Lohmann ${ }^{1,2}$, Alexander Akhmedov ${ }^{1,2}$, Remo Spescha ${ }^{1,2}$, Peter J. Elliott ${ }^{4}$, \\ Christoph H. Westphal ${ }^{4}$, Christian M. Matter ${ }^{1,2,3}$, Thomas F. Lüscher 1,2,3, \\ and Felix C. Tanner ${ }^{1,2,3 *}$
}

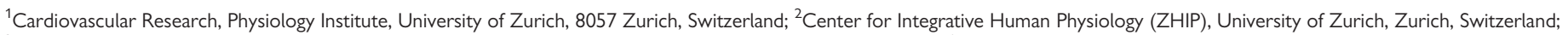

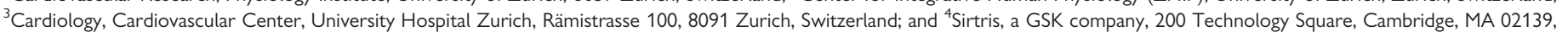
USA

Received 17 March 2010; revised 7 October 2010; accepted 21 October 2010; online publish-ahead-of-print 26 October 2010

Time for primary review: 32 days

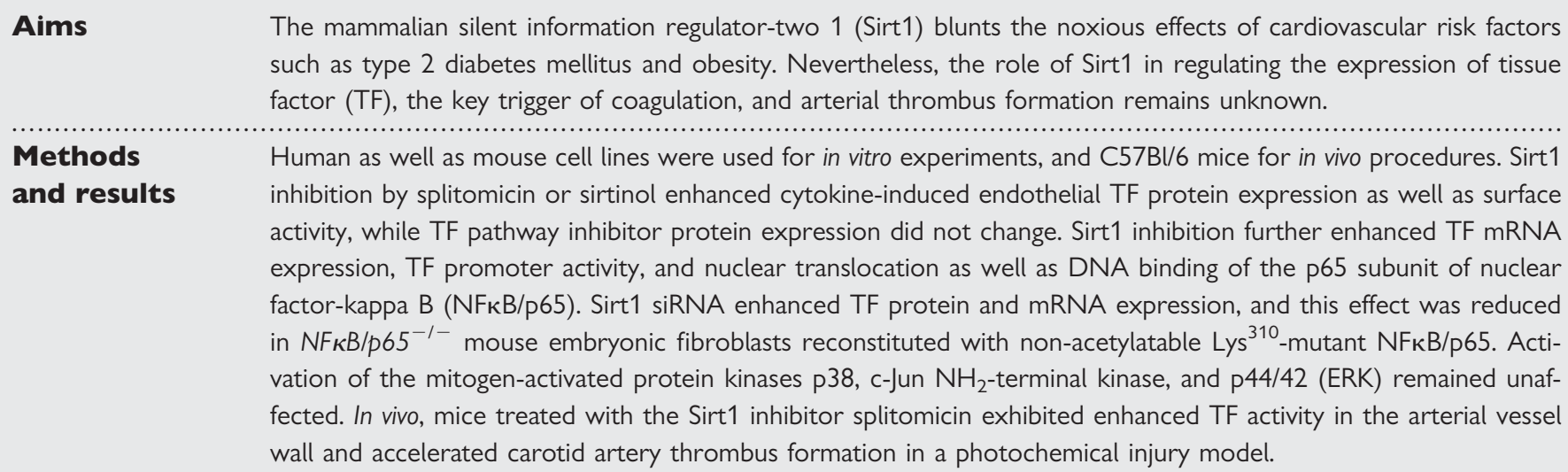

Conclusion $\quad$ We provide pharmacological and genetic evidence that Sirt1 inhibition enhances TF expression and activity by increasing NFkB/p65 activation in human endothelial cells. Furthermore, Sirt1 inhibition induces arterial thrombus formation in vivo. Hence, modulation of Sirt1 may offer novel therapeutic options for targeting thrombosis.

Keywords

Tissue factor • Sirt1 • Thrombosis • NFkB

\section{Introduction}

Cardiovascular diseases represent a major health burden. Acute vascular events such as myocardial infarction and ischaemic stroke account for the majority of deaths in Western countries. ${ }^{1}$ Formation of an arterial thrombus is the central event in such acute vascular syndromes. Tissue factor (TF) is the key trigger of the coagulation cascade and thereby crucially involved in arterial thrombosis. ${ }^{2-4}$ Its impact on thrombus formation may be enhanced in atherosclerosis since TF expression is induced in the inflammatory environment of atherosclerotic plaques. ${ }^{5}$ In line with this notion, clinical studies demonstrate higher TF levels in the culprit lesion of patients with acute coronary syndromes. ${ }^{6}$ Numerous inflammatory mediators such as tumour necrosis factor alpha $\left(\mathrm{TNF}-\alpha^{7}\right)$ or histamine, ${ }^{8}$ but also pro-thrombotic mediators like thrombin, ${ }^{9}$ induce endothelial TF expression by activating the MAP kinases p38, ERK, and c-Jun $\mathrm{NH}_{2}$-terminal kinase (JNK), and consequently transcription factors such as nuclear factor-kappa $\mathrm{B}(\mathrm{NF \kappa B}){ }^{2}$

Silent information regulator-two (Sir2) is an $\mathrm{NAD}^{+}$-dependent class III histone deacetylase. ${ }^{10}$ The mammalian sirtuins are evolutionarily conserved homologues of the yeast Sir $2{ }^{11}$ and silent information regulator-two 1 (Sirt1) is the closest orthologue. ${ }^{12}$ In addition to maintaining chromatin structure, ${ }^{10}$ Sirt1 has been shown to regulate transcription factors such as forkhead box class $\bigcirc$ (FOXO), ${ }^{13}$

t These authors contributed equally to this work.

* Corresponding author. Tel: +41 4425511 11; fax: +41 4463568 27, Email: felix.tanner@access.uzh.ch

Published on behalf of the European Society of Cardiology. All rights reserved. (C) The Author 2010. For permissions please email: journals.permissions@oup.com. 
$\mathrm{p} 53,{ }^{14}$ peroxisome proliferator-activated receptor- $\gamma,{ }^{15}$ endothelial nitric oxide synthase (eNOS), ${ }^{16}$ and $p 65$ subunit of nuclear factorkappa $B(N F \kappa B / p 65) .{ }^{17}$ Hence, Sirt1 is critically involved in cellular responses to stress, ${ }^{18}$ senescence, ${ }^{19}$ and mitochondrial function. ${ }^{20}$ Furthermore, endothelial overexpression of Sirt1 diminishes plaque formation in a mouse model of atherosclerosis, ${ }^{21}$ and pharmacological activation of Sirt1 improves glucose homeostasis in mice and humans. ${ }^{22}$ Based on these findings, Sirt1 modulators are under investigation in clinical trials for the treatment of patients with cardiovascular risk factors.

Since downstream targets of Sirt1 such as NFKB are involved in the regulation of TF expression, this study was designed to investigate the effect of Sirt1 on TF expression and arterial thrombus formation.

\section{Methods}

\subsection{Cell culture}

Human aortic endothelial cells (HAECs; Clonetics, Allschwil, Switzerland) were cultured as described. ${ }^{23}$ Briefly, adhering HAECs were grown to confluence and rendered quiescent for $24 \mathrm{~h}$ in medium containing $0.5 \%$ FCS before stimulation. Sirt $1^{-1-}$ mouse embryonic fibroblasts (MEFs) were kindly provided by David Sinclair (Harvard Medical School, Boston, MA, USA) and were grown to confluence in Dulbecco's modified Eagle's medium supplemented with $10 \%$ FCS. Similarly, NF $\kappa B / p 65^{-1-}$ MEFs with reconstituted wild-type $\mathrm{NF} \kappa \mathrm{B} / \mathrm{p} 65$ or non-acetylatable Lys $^{310}$-mutant $\mathrm{NF \kappa B} /$ p65 were used as described previously. ${ }^{24}$ Cells were pre-treated with splitomicin (Sigma, Buchs, Switzerland), sirtinol (Calbiochem, Lucerne, Switzerland), or resveratrol (Sigma) for $1 \mathrm{~h}$ before stimulation with 5 or $10 \mathrm{ng} / \mathrm{mL}$ TNF- $\alpha$ (R\&D Systems, Minneapolis, MN, USA), $1 \mathrm{U} /$ $\mathrm{mL}$ thrombin (R\&D Systems), or $10^{-5} \mathrm{~mol} / \mathrm{L}$ histamine (Sigma), respectively. Transient transfection with pcDNA3.1-SIRT1 or Sirt1 siRNA (Sirt1 siRNA oligonucleotide sequence: 5'-GATGAAGTTGACCTCCTCA-3') was performed using Lipofectamine Reagent (Invitrogen, Basel, Switzerland) or Lipofectamine RNAi MAX (Invitrogen), respectively, as described previously. ${ }^{15,25}$ Cytotoxicity was assessed by a colorimetric assay to detect lactate dehydrogenase (LDH; Roche, Basel, Switzerland).

\subsection{Western blot analysis}

Protein expression was determined as described. ${ }^{8}$ Antibodies against human TF, tissue factor pathway inhibitor (TFPI; both from American Diagnostica, Stamford, CT, USA), and Sirt1 (Santa Cruz Biotechnology, Santa Cruz, CA, USA) were used at 1:2000 dilution. Antibodies against phosphorylated p38 mitogen-activated protein (MAP) kinase (p38), p44/ 42 MAP kinase (ERK), and JNK (all from Cell Signaling, Danvers, MA, USA) were used at 1:1000, 1:5000, and 1:1000 dilution, respectively. Antibodies against total p38, ERK, and JNK (all from Cell Signaling) were diluted to 1:3000, 1:10000, and 1:1000, respectively. The antibody against IкB- $\alpha$ (Santa Cruz Biotechnology) was applied at a 1:1000 dilution. Alpha-tubulin (Sigma) were applied to control protein loading (1:10 000 dilution). Primary antibodies were detected with a horseradish peroxidase-linked secondary antibody (Amersham, Munich, Germany).

\subsection{Real-time PCR}

Total RNA was extracted from HAECs with $1 \mathrm{~mL}$ TRIzol Reagent (Invitrogen) as described. ${ }^{23}$ Conversion of total cellular RNA to cDNA was carried out with Moloney murine leukaemia virus reverse transcriptase and random hexamer primers (Amersham) in a final volume of $33 \mu \mathrm{L}$ using $4 \mu \mathrm{g}$ of RNA. The total cDNA pool obtained served as template for subsequent $P C R$ amplification with primers specific for full-length TF (sense primer: 5'-TCCCCAGAGTTCACACCTTACC-3', antisense primer: 5'-CCTTTCTCCTGGCCCATACAC-3'; bases 508-529 of F3 cDNA; NCBI no. NM 001993). Real-time PCR amplification was performed in an MX3000P PCR cycler (Stratagene) using the SYBR Green JumpStart kit (Sigma) in $25 \mu \mathrm{L}$ final reaction volume containing $2 \mu \mathrm{L}$ cDNA, $10 \mathrm{pmol}$ of each primer, $0.25 \mu \mathrm{L}$ of internal reference dye, and $12.5 \mu \mathrm{L}$ of JumpStart Taq ReadyMix (buffer, dNTP, stabilizers, SYBR Green, Taq polymerase, and JumpStart Taq antibody). A melting curve analysis was performed after amplification to verify the accuracy of the amplicon. Ribosomal L28 RNA in HAECs or S12 RNA in MEFs served as loading control.

\subsection{TF activity in vitro}

TF surface activity in HAECs was analysed using a colorimetric assay (American Diagnostica). Cells were incubated at $37^{\circ} \mathrm{C}$ with human FVIla and FX, allowing for the formation of the TF/FVIla complex at the cell surface. Conversion of FX to FXa was measured by the ability of FXa to cleave a chromogenic substrate. A standard curve was established with lipidated human TF to assure that the results were in the linear range of detection.

\subsection{Histone deacetylase activity}

Cell-based histone deacetylase activity (HDAC) assay was performed according to the manufacturer's instructions (BIOMOL, Hamburg, Germany). Briefly, HAECs were starved in phenol-red-free media containing $0.5 \%$ FCS. After $24 \mathrm{~h}$, cells were incubated with $200 \mu \mathrm{mol} / \mathrm{L}$ Fluor de Lys substrate with or without trichostatin A (TSA; $1 \mu \mathrm{mol} / \mathrm{L}, \mathrm{BIOMOL}$ ), and with or without splitomicin $(100 \mu \mathrm{mol} / \mathrm{L}$, Sigma). After $2 \mathrm{~h}$, cells were incubated with Fluor de Lys developer, lysed after $30 \mathrm{~min}$, and equal amount of lysates were analysed for enzyme activity using a fluorescence reader (Ex. 360 nm, Em. 460 nm).

\subsection{TF promoter activity}

An adenoviral vector (Ad5/hTF/Luc) containing the minimal TF promoter $(-227$ to +121 bp) upstream of the Luciferase cDNA and the SV40 PolyA signal was prepared as described. ${ }^{26}$ For viral transfection, the vector was added to HAEC at 100 pfu/cell for $1 \mathrm{~h}$. HAEC were kept in growth medium for $24 \mathrm{~h}$ and then serum-starved for $24 \mathrm{~h}$ prior to TNF- $\alpha$ stimulation with or without Sirt1 inhibitor pre-treatment. Cells were stimulated with TNF- $\alpha$ for 30 min. Firefly luciferase activity was determined in cell lysates using a luminometer (Bertholg Technologies, Bad Wildbad, Germany).

\subsection{NFkB DNA binding assay and NFkB/p65 immunofluorescence}

Adhering HAECs were pre-treated with Sirt 1 inhibitors for $1 \mathrm{~h}$, followed by stimulation with $10 \mathrm{ng} / \mathrm{mL}$ TNF- $\alpha$ for additional $30 \mathrm{~min}$. Nuclear protein was obtained by using a nuclear extraction kit (Active Motif, Rixensart, Belgium). Cells were harvested in hypotonic buffer for $15 \mathrm{~min}$ before centrifugation, isolated nuclei were resuspended in a hypertonic buffer, and nuclear protein was extracted by incubation on a rotator for $30 \mathrm{~min}$. The supernatant containing the nuclear protein was collected after centrifugation. The DNA binding reaction was carried out with $5 \mu \mathrm{g}$ of nuclear protein in a 96 -well plate coated with consensus sequences for NFKB (GGGACTTTCC) for $1 \mathrm{~h}$ at room temperature. After washing, NFKB/p65 antibody (Active Motif) was added and incubated for $1 \mathrm{~h}$, followed by incubation with a horseradish peroxidase-conjugated secondary antibody. Finally, NFKB/p65 DNA binding was assessed spectrophotometrically at $450 \mathrm{~nm}$.

HAECs were stained with FITC-labelled mouse anti-NFkB/p65 (Santa Cruz Biotechnology). Cytoplasmic NFkB/p65 was analysed using an SP2 confocal microscope (Leica), and quantification performed with the opensource software CellProfiler. ${ }^{27}$ Intensity of the green channel was measured in the cytoplasm (nuclear area subtracted from the total cell area) of at least 150 cells per treatment group at the Z-section where the nuclei had their largest diameter. 


\subsection{NFkB/p65 immunoprecipitation}

HAECs were treated with $50 \mu M$ SIRT1 or scrambled siRNA overnight, followed by stimulation with TNF- $\alpha(10 \mathrm{ng} / \mathrm{mL})$ for $20 \mathrm{~min}$. Cells were then harvested and protein extracted in lysis buffer $(20 \mathrm{mM}$ HEPES, $\mathrm{pH}$ 7.5, $80 \mathrm{mM} \mathrm{NaCl}, 2.5 \mathrm{mM} \mathrm{MgCl}$, 1 mM EDTA, 0.5\% NP-40, 1 mM phenylmethylsulfonyl fluoride, $10 \mu \mathrm{g} / \mathrm{mL}$ aprotinin, $10 \mu \mathrm{g} / \mathrm{mL}$ leupeptin, and $100 \mu \mathrm{M}$ splitomicin). One milligram whole-cell lysates were immunoprecipitated with rabbit anti-NFKB/p65 (Santa Cruz) using Protein G agarose (Millipore, Zug, Switzerland). Immunoprecipitated samples were immunoblotted with rabbit anti-acLys ${ }^{310} \mathrm{NFkB} / \mathrm{p} 65$ (Abcam, Cambridge, UK), the total lysates (5\% input) with rabbit anti-SIRT1 and rabbit anti-NFKB/p65 (both from Santa Cruz Biotechnology).

\subsection{Carotid artery thrombosis model and TF activity in vivo}

The investigation conforms to the Guide for the Care and Use of Laboratory Animals published by the US National Institutes of Health (NIH Publication no. 85-23, revised 1996). All animal procedures were approved by the local animal committee (Kantonales Veterinäramt Zurich, Switzerland) and performed in accordance with our institutional guidelines. C57BL/6 mice aged 12-14 weeks weighing on average $27 \mathrm{~g}$ were anaesthetized by intraperitoneal injection of $87 \mathrm{mg} / \mathrm{kg}$ sodium pentobarbital (Butler, Columbus, OH, USA). Rose Bengal (Fisher Scientific, Fair Lawn, NJ, USA) was diluted to $12 \mathrm{mg} / \mathrm{mL}$ in phosphate-buffered saline and then injected into the tail vein at a concentration of $63 \mathrm{mg} / \mathrm{kg}$. Mice were secured in a supine position, placed under a dissecting microscope, and the right common carotid artery was exposed following a midline cervical incision. A Doppler flow probe (Model 0.5 VB, Transonic Systems, Ithaca, NY, USA) was applied and connected to a flowmeter (Transonic, Model T106). Six minutes after Rose Bengal injection, a $1.5 \mathrm{~mW}$ green light laser (540 nm; Melles Griot, Carlsbad, CA, USA) was applied to the site of injury at a distance of $6 \mathrm{~cm}$ for $60 \mathrm{~min}$ or until thrombosis occurred. From the onset of injury, blood flow was monitored up to $120 \mathrm{~min}$, at which time the experiment was terminated. ${ }^{7}$ Occlusion was defined as flow $\leq 0.1 \mathrm{~mL} / \mathrm{min}$ for at least $1 \mathrm{~min}$. Mice were divided into two groups: splitomicin $(80 \mathrm{mg} / \mathrm{kg}$ with an intraperitoneal injection every $24 \mathrm{~h}$ for 5 days), or vehicle control ( $0.5 \%$ methylcellulose).

Right carotid arteries were homogenized in $50 \mu \mathrm{L}$ of lysis buffer and left to stand on ice for $30 \mathrm{~min}$. TF activity was measured by using the colorimetric assay as described above.

\subsection{Statistical analysis}

Data are indicated as mean \pm SEM. Unpaired Student's t-test was used to evaluate differences between two groups. For statistical analysis of data from multiple groups, one-way ANOVA was performed. A $P$ value $<0.05$ denoted a significant difference. All statistical values are additionally summarized in the Supplementary material online, Table S1.

\section{Results}

\subsection{Sirt1 inhibition enhances TF expression and activity}

TF protein expression was determined in TNF- $\alpha$ ( $5 \mathrm{ng} / \mathrm{mL}$ for $5 \mathrm{~h}$ ) stimulated HAECs in the presence or absence of increasing concentrations of splitomicin $(25-200 \mu \mathrm{mol} / \mathrm{L})$ or sirtinol $(15-60 \mu \mathrm{mol} / \mathrm{L})$, respectively. Both inhibitors enhanced TNF- $\alpha$-induced TF protein expression in a concentration-dependent manner; maximal activation occurred at $100 \mu \mathrm{mol} / \mathrm{L}$ in splitomicin and at $30 \mu \mathrm{mol} / \mathrm{L}$ in sirtinoltreated cells, respectively $(n=4 ; P<0.05$; Figure $1 \mathrm{~A}$ and $C)$. These effects were paralleled by an increased TF surface activity in cells pretreated with either Sirt1 inhibitor $(n=4 ; P<0.01$, Figure $1 B$ and $D)$.
Sirt1 knockdown using specific siRNA enhanced TNF- $\alpha$-induced TF protein expression ( $n=4 ; P<0.01$; Figure $1 E$ ); western blot analysis confirmed reduced Sirt1 expression in cells transfected with Sirt1 siRNA $(n=4 ; P<0.01$; Figure $1 F)$. Sirt1 inhibition also enhanced TF protein expression in response to stimulation with histamine $\left(10^{-5} \mathrm{~mol} / \mathrm{L}\right)$ or thrombin $(1 \mathrm{U} / \mathrm{mL})$, respectively $(n=4 ; P<0.05$; Figure 2A). The expression of TFPI, the physiological antagonist of TF, remained unaffected $(n=4 ; P=N S$; Figure $2 B)$. TNF- $\alpha$ did not alter endogenous Sirt1 protein expression $(n=4 ; \quad P=N S$; Figure 2C), and no changes in cell morphology nor LDH release were detected by any of these treatments ( $n=4$ for each; $P=N S$; Supplementary material online, Figure S1).

\subsection{TF mRNA expression is induced by Sirt1 inhibition}

Real-time rtPCR revealed that TNF- $\alpha(5 \mathrm{ng} / \mathrm{mL})$ induced TF mRNA expression within $1 \mathrm{~h}(n=4 ; P<0.05$; Figure $3 A)$. Both splitomicin and sirtinol enhanced TF mRNA expression in stimulated endothelial cells (splitomicin: $n=4 ; P<0.05$; Figure 3A, sirtinol: $n=4 ; P<0.05$; Figure $3 B$ ). In parallel, Sirt1 knockdown using siRNA enhanced TNF- $\alpha$-stimulated TF mRNA expression ( $n=4 ; P<0.01$; Figure $3 C$ ).

\subsection{Sirt1 inhibition reduces HDAC class III activity}

A cell-based HDAC assay was performed in HAECs to confirm that the Sirt1 inhibitor splitomicin diminishes intracellular deacetylase activity. Cells were treated with $1 \mu \mathrm{mol} / \mathrm{L}$ TSA to inactivate HDAC classes I and II in the presence or absence of splitomicin (100 $\mu \mathrm{mol} / \mathrm{L})$. Consistent with inhibition of HDAC class III, splitomicin reduced deacetylase activity $(n=4 ; P<0.05$; Supplementary material online, Figure S2A) as compared with TSA alone. In contrast, splitomicin did not affect TF protein expression in Sirt $1^{-1-}$ MEFs $(n=4 ; P=$ NS; Supplementary material online, Figure S2B).

\subsection{Activation of Sirt1 impairs TF expression and activity}

Pharmacological activation of Sirt1 by resveratrol, a commonly used, but less specific Sirt1 activator, impaired TNF- $\alpha$-induced TF protein and mRNA expression $(n=4 ; P<0.01$ for TF protein, and $P<$ 0.05 for TF mRNA; Supplementary material online, Figure S3A and B). In parallel, overexpression of Sirt1 in Sirt1 ${ }^{-1-}$ MEFs reduced TNF- $\alpha$-induced TF expression $(n=4 ; \quad P<0.01$; Supplementary material online, Figure S3C and D).

\subsection{Sirt1 inhibition enhances TF promoter activity}

To assess whether Sirt1 inhibition enhances TF promoter activity, the impact of splitomicin and sirtinol on the TF promoter was analysed. HAECs were transfected with a luciferase plasmid under control of the human minimal TF promoter ( -221 up to +121 bp). Splitomicin and sirtinol enhanced stimulated TF promoter activity as compared with TNF- $\alpha$ alone $(n=5 ; P<0.01$; Figure $4 A$ and $B)$.

\subsection{MAP kinase activation is not affected by Sirt1 inhibition}

To assess whether modulation of Sirt1 activity alters MAP kinase activation, HAECs were examined at different time points after TNF- $\alpha$ stimulation. The MAP kinases $\mathrm{p} 38$, ERK, and JNK were transiently 

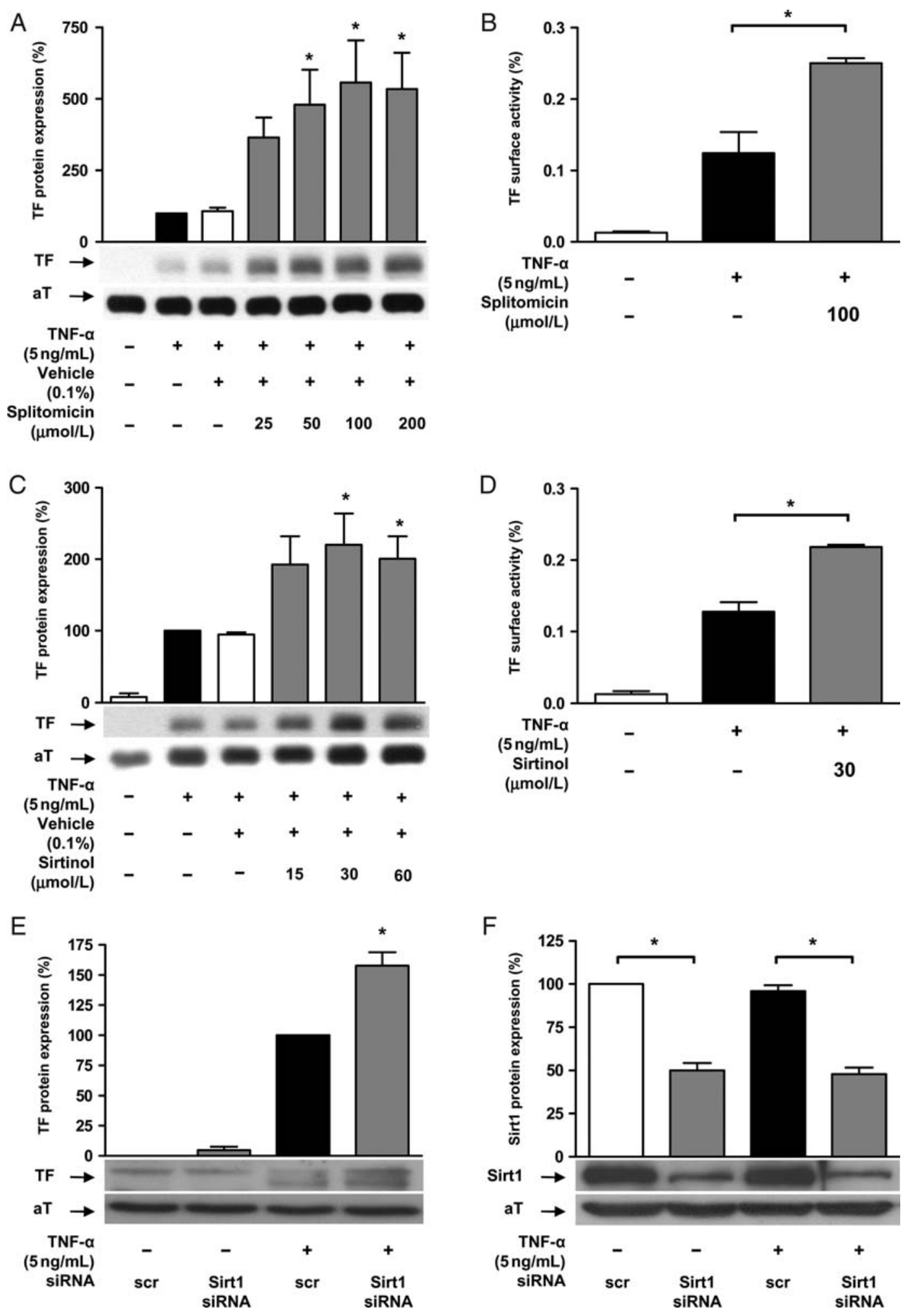

Figure I Sirt1 inhibition enhances endothelial TF expression and activity. ( $A$ and B) Splitomicin enhances TNF- $\alpha$-induced TF protein expression $(* P<0.05$ vs. TNF- $\alpha$ alone) and surface activity $(* P<0.01$ vs. TNF- $\alpha$ alone) in human endothelial cells. $(C$ and $D)$ Sirtinol exerts similar effects on TF protein expression ( ${ }^{*} P<0.05$ vs. TNF- $\alpha$ alone) and activity ( ${ }^{*} P<0.01$ vs. TNF- $\alpha$ alone). ( $E$ and $F$ ) Sirt1 siRNA enhances TNF- $\alpha$-induced TF protein expression (*P $<0.01$ vs. TNF- $\alpha$ alone). 

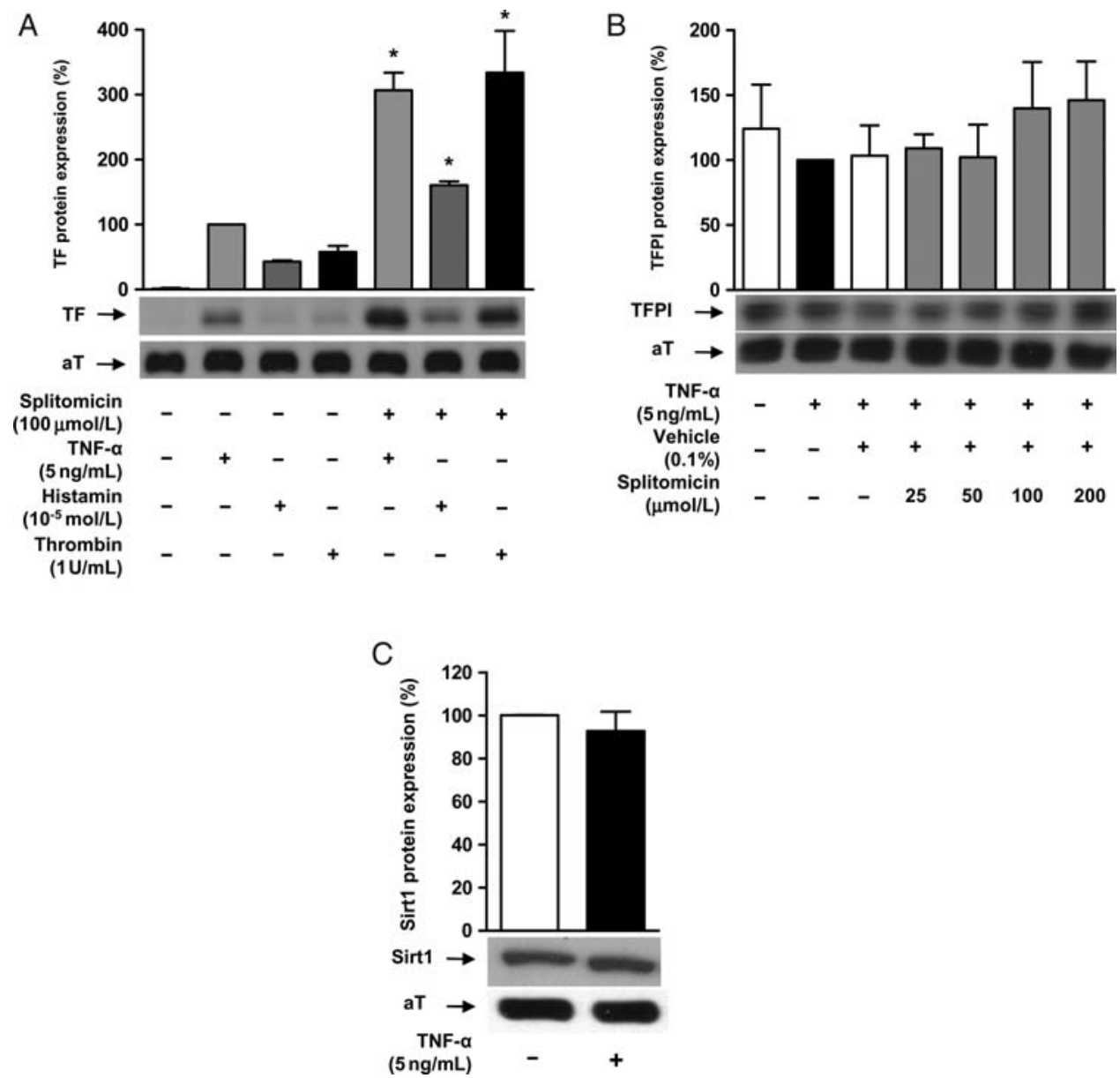

Figure 2 Splitomicin induce TF expression in response to different mediators, but does not alter TFPI expression. TNF- $\alpha$ does not alter Sirt1 expression. (A) TNF- $\alpha$, histamine, and thrombin induce TF protein expression. Splitomicin up-regulates TF expression in response to each stimulus (*P $<0.05$ vs. each stimulation factor). (B) Splitomicin does not alter TFPI expression ( $P=N S)$. (C) TNF- $\alpha$ stimulation does not change endogenous expression of Sirt1 ( $P=\mathrm{NS})$.

activated by TNF- $\alpha$ ( $n=3$; Supplementary material online, Figures $S 4$ and S5). Phosphorylation of $\mathrm{p} 38$, ERK, and JNK remained unaffected in cells pre-treated with either splitomicin $(n=3 ; P=N S$; Supplementary material online, Figure S4) or sirtinol, respectively $(n=3 ; P=$ NS; Supplementary material online, Figure S5). Total expression of MAP kinases remained unchanged at any time point with or without Sirt1 inhibitors.

\subsection{Sirt1 inhibition enhances NFkB/p65 DNA binding via deacetylation of Lys ${ }^{310}$ of NFkB/p65}

$\mathrm{NF} \mathrm{KB} / \mathrm{p} 65$ is a transcription factor that regulates TF expression. Thus, the effect of Sirt1 inhibition on NFKB/p65 activation was investigated. TNF- $\alpha(10 \mathrm{ng} / \mathrm{mL})$ induced a significant increase in NFKB/p65 DNA binding as compared with control $(n=5 ; P<0.01$; Figure $5 \mathrm{~A}$ and $B)$. Sirt1 inhibition with splitomicin $(100 \mu \mathrm{mol} / \mathrm{L})$ or sirtinol $(30 \mu \mathrm{mol} / \mathrm{L})$ enhanced NFKB/p65 DNA binding $(n=5 ; P<0.01$; Figure $5 A$ and $B$ ). In line with this, translocation of $N F \kappa B / p 65$ from the cytoplasm to the nucleus was increased after TNF- $\alpha$ stimulation as confirmed by $\mathrm{NF} \mathrm{B} / \mathrm{p} 65$ immunofluorescence and pre-treatment with splitomicin further enhanced $\mathrm{NF \kappa B} / \mathrm{p} 65$ nuclear translocation ( $n=5 ; P<0.01$; Supplementary material online, Figure S6).

Since degradation of the inhibitory protein of $N F_{\kappa} B, I_{\kappa} B-\alpha$, is an early step in activation of $\mathrm{NF \kappa B} / \mathrm{p} 65$, the effect of Sirt1 inhibition on I $\mathrm{B}-\alpha$ degradation was investigated. TNF- $\alpha$ induced a transient degradation of $I_{\kappa} B-\alpha \quad(n=3$; Supplementary material online, Figures $S 4$ and S5). Neither splitomicin nor sirtinol altered the degradation pattern of I $\mathrm{K}-\alpha$ as compared with TNF- $\alpha$ alone ( $n=3 ; P=N S$; Supplementary material online, Figures $\mathrm{S} 4$ and S5).

For further analysis, $N F \kappa B / p 65^{-1-}$ MEFs were used and reconstituted with either wild-type $\mathrm{NF} \kappa \mathrm{B} / \mathrm{p} 65$ or a non-acetylatable Lys ${ }^{310}$. mutant NFkB/p65. The effect of Sirt1 siRNA on TF expression was less pronounced in MEFs reconstituted with the non-acetylatable Lys $^{310}$-mutant $\mathrm{NF \kappa B} / \mathrm{p} 65$ as compared with the wild-type NFkB/p65 $(n=5 ; P<0.01$; Figure 5C), although both types of reconstituted cells exhibited enhanced TF mRNA expression after TNF- $\alpha$ stimulation when Sirt1 was knocked down by siRNA ( $n=5$; $P<0.05$; Figure $5 C$ ). Western blot analysis confirmed reduced Sirt1 expression in all the cells transfected with Sirt1 siRNA ( $n=4 ; P<0.05$; Figure 5D).

Sirt1 was also silenced in HAECs using siRNA. The cells were stimulated with TNF- $\alpha \quad(10 \mathrm{ng} / \mathrm{mL})$ and a NFKB/p65 

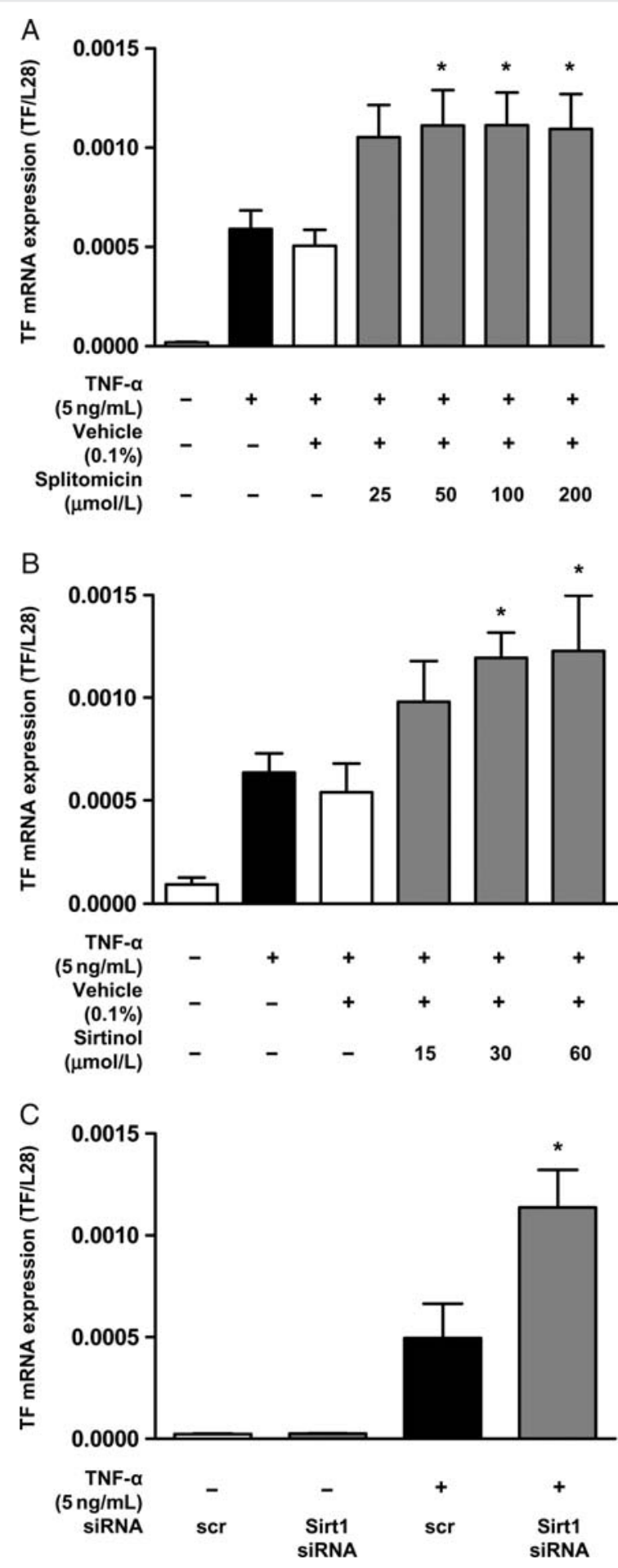

Figure 3 Sirt1 inhibition induces endothelial TF expression at the transcriptional level. ( $A$ and $B$ ) Real-time rtPCR reveals that splitomicin and sirtinol enhance TNF- $\alpha$-induced TF mRNA expression $(* P<0.05$ vs. TNF- $\alpha$ alone for splitomicin; $* P<0.05$ vs. TNF- $\alpha$ alone for sirtinol). (C) Sirt1 siRNA enhances TNF- $\alpha$-induced TF mRNA expression ( $* P<0.01$ vs. TNF- $\alpha$ alone).
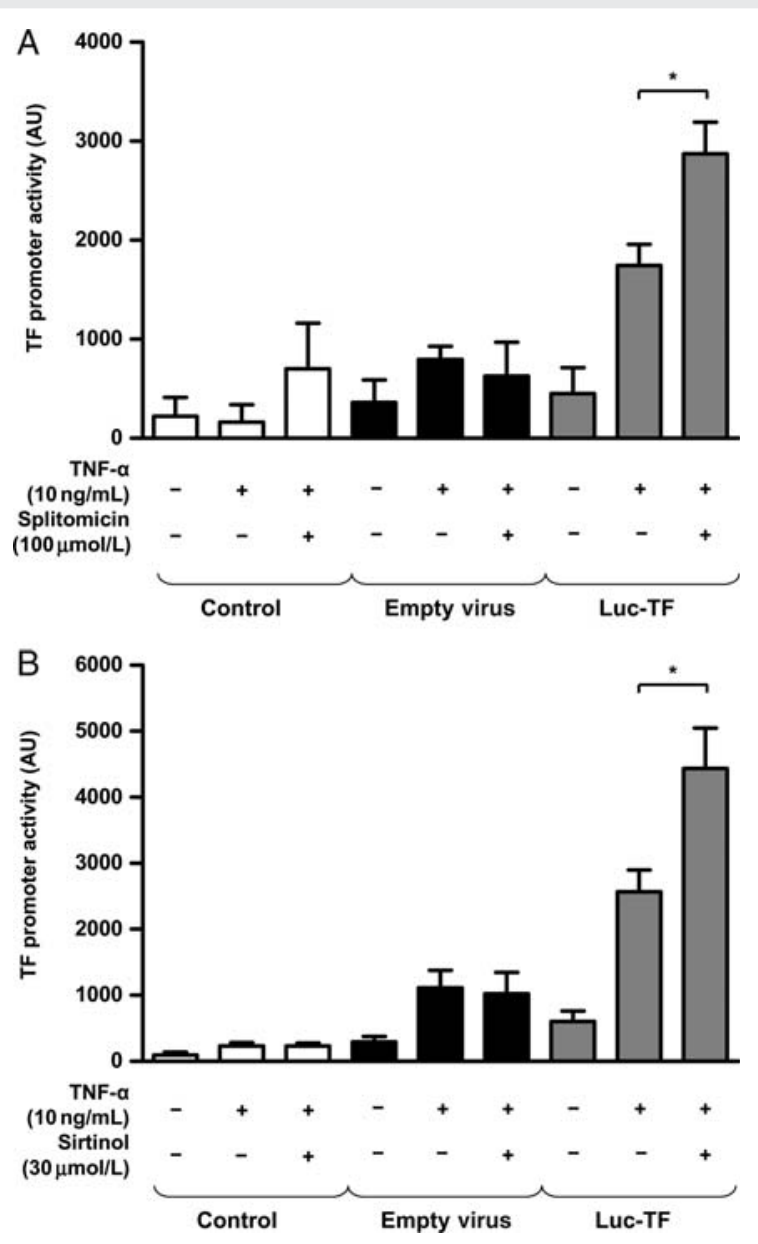

Figure 4 Sirt1 inhibition increases TF promoter activity. ( $A$ and $B$ ) TNF- $\alpha$ increases the activity of the minimal TF promoter. Splitomicin (A) and sirtinol (B) enhance TF promoter activity under cytokine-induced conditions ( $* P<0.01$ vs. TNF- $\alpha$ alone). AU, arbitrary units.

immunoprecipitation was performed. There was a higher extent of Lys $^{310} \mathrm{NF} \mathrm{KB} / \mathrm{p} 65$ acetylation in cells with impaired Sirt1 expression $(n=3$; Figure $5 E)$.

\subsection{Sirt1 inhibition induces TF activity and arterial thrombosis in vivo}

C57Bl/6 mice were treated with splitomicin $(80 \mathrm{mg} / \mathrm{kg}$ body weight, intraperitoneal injection every $24 \mathrm{~h}$ for 5 days) or vehicle $(0.5 \%$ methylcellulose). Vehicle-treated mice developed carotid artery thrombosis within a mean occlusion time of 57.8 . $\pm 7.5 \mathrm{~min}$, while splitomicin-treated mice occluded within a mean time period of $31.2 \pm 5.3 \min (n=7 ; P<0.05$; Figure $6 \mathrm{~A})$. Initial blood flow in carotid artery did not differ between vehicle- and splitomicin-treated mice $(0.54 \pm 0.05$ vs. $0.52 \pm 0.05 \mathrm{~mL} / \mathrm{min} ; n=7 ; P=N S$; Figure $6 B)$. Splitomicin treatment increased TF activity in mouse carotid artery in vivo as compared with the controls $(n=6 ; P<0.05$; Figure $6 C)$. 
A

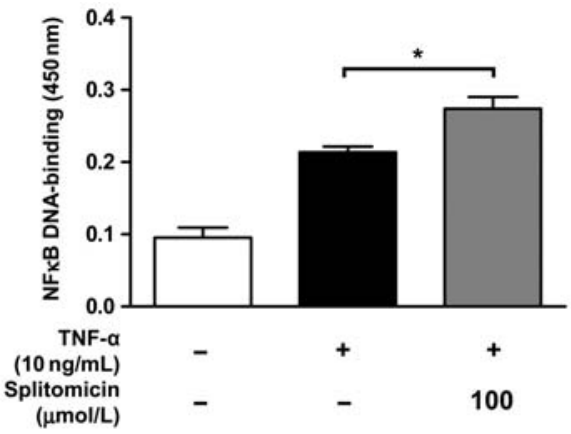

C

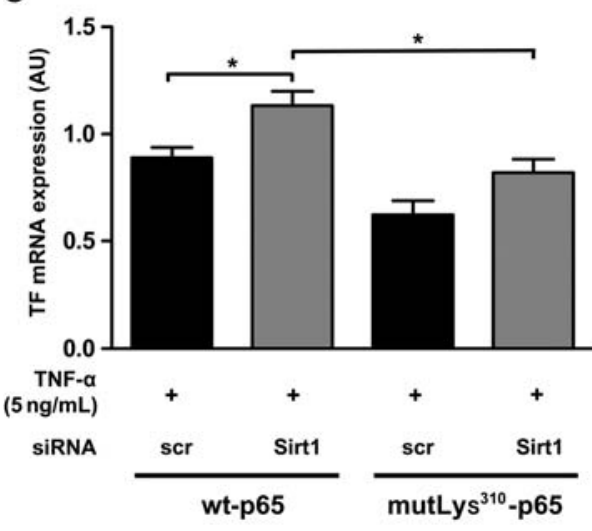

B

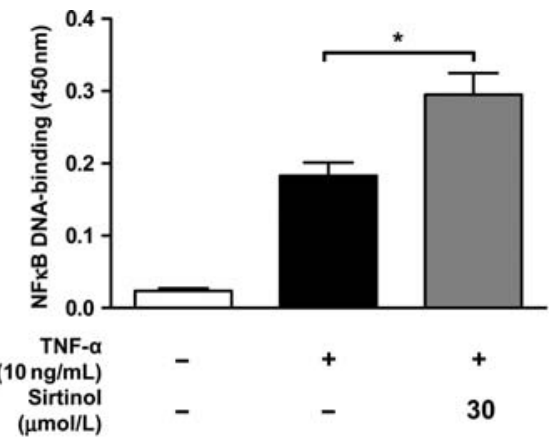

D

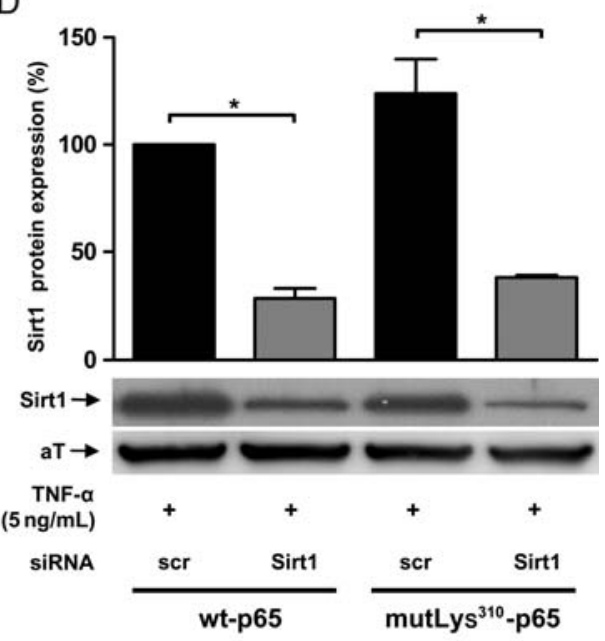

E

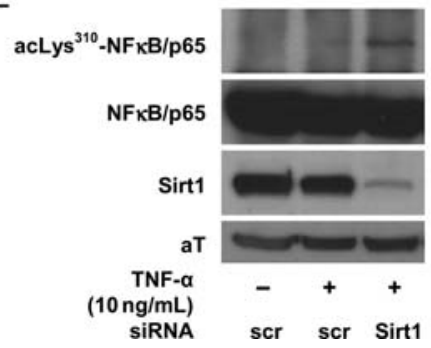

Figure 5 Sirt1 inhibition enhances NFkB/p65 activation via acetylation of Lys ${ }^{310}$ of NFkB/p65. (A and B) TNF- $\alpha$ stimulates NFkB/p65 DNA binding activity as compared with control conditions. Splitomicin and sirtinol both enhance NFKB/p65 DNA binding (*P<0.01 vs. TNF- $\alpha$ alone). (C) Sirt1 siRNA induces TF mRNA up-regulation in the presence of wild-type NFKB/p65, whereas its expression is reduced by a non-acetylatable Lys ${ }^{310}$-mutant

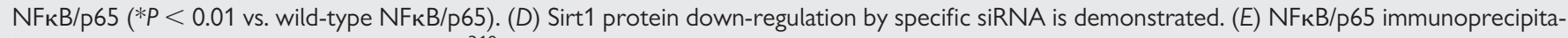
tion in HAECs reveals more acetylated Lys ${ }^{310}$ NFKB/p65 upon Sirt1 siRNA treatment.

\section{Discussion}

The present study demonstrates that Sirt1 inhibits TF expression at the transcriptional level via NFkB/p65 in human vascular cells. Furthermore, it shows that inhibition of Sirt1 induces thrombus formation and arterial TF activity in vivo.

To inhibit Sirt1 activity in human vascular cells, two different pharmacological agents were applied. Both splitomicin and sirtinol are established inhibitors of Sirt1. ${ }^{11,28-30}$ It is still debated to what extent these drugs specifically inhibit Sirt1; indeed, sirtinol may also inhibit Sirt2. ${ }^{30}$ Nevertheless, the concentrations of both substances applied in this study are within the established range. ${ }^{17,19}$ Moreover, splitomicin did not alter TF expression in Sirt $1^{-1-}$ MEFs, and TF was increased when Sirt1 was down-regulated by siRNA. Hence, these data support the conclusion that Sirt1 regulates the expression of TF.

Cytokine-mediated TF expression is mainly regulated at the transcriptional level, where NFKB/p65 is importantly involved. ${ }^{2}$ Transcriptionally active NFKB consists of a heterodimeric complex mainly composed of a p65 and a p50 subunit. In quiescent cells, NFKB is retained in the cytoplasm by its inhibitor $І_{\kappa} B$. Upon cytokine stimulation, ІкB becomes degraded allowing NFKB to translocate to the nucleus and to stimulate gene transcription. In this study, both Sirt1 inhibitors enhanced nuclear translocation and DNA binding of NFKB/ p65, identifying $N F \kappa B / p 65$ as a downstream target of Sirt1 in the context of TF expression. Since the Sirt1 inhibitors did not affect MAP kinases nor $1 \kappa B$ degradation, an involvement of these mediators can be ruled out; thus, a direct effect of Sirt1 on NFKB/p65 seems 

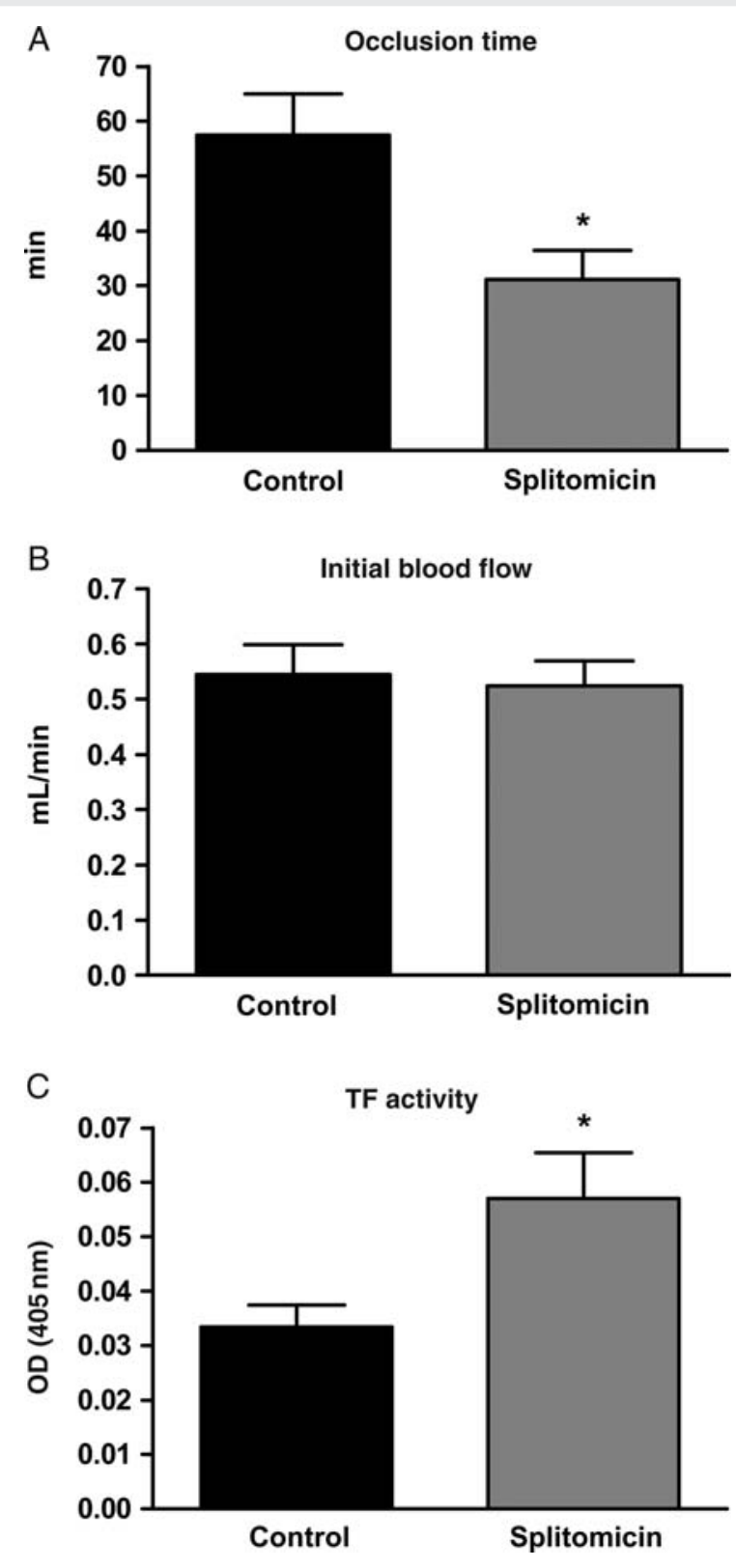

Figure 6 Sirt1 inhibition accelerates arterial thrombus formation. (A) Time to thrombotic occlusion after mouse carotid artery photochemical injury in vivo. Splitomicin promotes thrombus formation $(* P<0.05$ vs. vehicle alone). (B) Initial blood flow in the carotid artery is unchanged $(P=N S)$. ( $C$ ) Splitomicin increases TF activity in mouse carotid artery in vivo. Values are indicated as absorbance at $405 \mathrm{~nm}(* \mathrm{P}<0.05$ vs. vehicle).

likely. Acetylation of $L y s^{310}$ and $L y s^{221}$ residues of NFKB/p65 impairs its association with $1 \kappa B$ and increases its DNA-binding capacity. ${ }^{31}$ Sirt1 deacetylates $\mathrm{Lys}^{310}$ of the NFKB/p65 subunit in different cell types and thereby blunts $N F_{\kappa} B / p 65$-mediated gene expression. ${ }^{17,32}$ Experiments involving $N F \kappa B / p 65^{-1-}$ MEFs reconstituted with either wildtype NFKB/p65 or non-acetylatable Lys ${ }^{310}$-mutant NFKB/p65, respectively, demonstrate that regulation of TF mRNA expression by Sirt1 indeed depends on Lys ${ }^{310}$ acetylation of NFKB/p65. Nevertheless, other downstream targets of Sirt1, such as eNOS or p53, are also known to regulate TF expression, ${ }^{33,34}$ and a role of these regulators in Sirt1-mediated TF expression in addition to that of $N F \kappa B / p 65$ cannot be ruled out by the current data.

TF is the key initiator of coagulation and therefore an important trigger of thrombosis. ${ }^{35}$ Exposure of TF to the circulating blood results in acute thrombosis and eventually vascular occlusion; in fact, reducing TF expression impairs thrombus formation. ${ }^{36}$ To investigate arterial thrombosis in vivo, a photochemical vascular injury model was used, since it is an established method to study TF-dependent thrombus formation. ${ }^{36}$ Mean occlusion time in splitomicin-treated mice was reduced by nearly $50 \%$, supporting the concept that inhibition of Sirt1 induces arterial thrombosis. The increased TF activity in mouse carotid artery indicates that Sirt1 inhibition regulates thrombosis at least in part via activation of TF in vivo. TFPI, the physiological inhibitor of TF, was not affected by splitomicin treatment excluding compensatory effects on TF activity. Given the importance of the balance between TF and TFPI for thrombosis, ${ }^{37}$ these findings underscore a role for TF in the modulation of thrombus formation by Sirt1. Hence, Sirt1 activators, which are currently under investigation for the treatment of type 2 diabetes mellitus, may possess additional protective cardiovascular effects by inhibiting arterial thrombus formation.

Sirt1 inhibition resulted in an enhanced TF expression after stimulation with different mediators. Hence, Sirt1 may suppress TF expression especially in the inflammatory environment observed in patients exposed to cardiovascular risk factors and with advanced atherosclerotic lesions. ${ }^{38}$ Indeed, elevated levels of soluble TF are observed in patients with atherosclerosis as compared with controls. ${ }^{39}$ Furthermore, even higher concentrations are measured in the area around the culprit lesion in patients with unstable angina or acute myocardial infarction as compared with patients with stable angina. ${ }^{6,40}$ Taken together, pharmacological or genetic activation of Sirt1 could be a promising therapeutic target in these conditions.

A recent report described that endothelial overexpression of Sirt1 diminishes atherogenesis in ApoE-deficient mice, suggesting an antiatherosclerotic effect of Sirt1. ${ }^{21}$ In addition, Sirt1 exerts beneficial effects on cardiovascular risk factors such as type 2 diabetes mellitus and arterial hypertension. ${ }^{22,41,42}$ Sirt1 also mediates the effects of caloric restriction on life-span extension, ${ }^{43}$ which may in turn improve endothelial function and blood pressure regulation. ${ }^{44}$ Since TF expression and activity is increased by cardiovascular risk factors such as type 2 diabetes mellitus ${ }^{45,46}$ and arterial hypertension, ${ }^{47}$ Sirt1 activators, which are currently under investigation in clinical trials for the treatment of cardiovascular risk factors, could exert a dual beneficial effect preventing arterial thrombosis not only by down-regulating TF expression, but also by interfering with the risk factors inducing it.

In summary, this study demonstrates that Sirt1 inhibition enhances TF in vitro as well as in vivo, and accelerates arterial thrombus formation. Sirt1 exerts these effects at the transcriptional level by modulating NFKB/p65 DNA binding without affecting MAP kinase activation. These findings reveal a novel action of Sirt1 and suggest that Sirt1 activators may be applied for the prevention of thrombosis.

\section{Acknowledgements}

We thank the Center for Microscopy and Image Analysis (University of Zurich, Switzerland) for using their resources. 
Conflict of interest: none declared.

\section{Funding}

This study was supported by the Swiss National Science Foundation (grant no. 3200B0-113328/1 to F.C.T., grant no. 3100-068118.02/1 to T.F.L., and grant no. 31-114094/1 to C.M.M.; Berne, Switzerland), the Bonizzi-Theler Foundation (Zurich, Switzerland), Velux Foundation (Zurich, Switzerland), Wolfermann Nägeli Foundation (Zurich, Switzerland), MERCATOR Foundation (Essen, Germany), and the Swiss Heart Foundation (Berne, Switzerland).

\section{References}

1. Rosamond W, Flegal K, Furie K, Go A, Greenlund K, Haase N et al. Heart disease and stroke statistics-2008 update: a report from the American Heart Association Statistics Committee and Stroke Statistics Subcommittee. Circulation 2008;117:e25-e146.

2. Steffel J, Luscher TF, Tanner FC. Tissue factor in cardiovascular diseases: molecular mechanisms and clinical implications. Circulation 2006;113:722-731.

3. Tilley R, Mackman N. Tissue factor in hemostasis and thrombosis. Semin Thromb Hemost 2006;32:5-10.

4. Toschi V, Gallo R, Lettino M, Fallon JT, Gertz SD, Fernandez-Ortiz A et al. Tissue factor modulates the thrombogenicity of human atherosclerotic plaques. Circulation 1997;95:594-599.

5. Wilcox JN, Smith KM, Schwartz SM, Gordon D. Localization of tissue factor in the normal vessel wall and in the atherosclerotic plaque. Proc Natl Acad Sci USA 1989; 86:2839-2843.

6. Ardissino D, Merlini PA, Ariens R, Coppola R, Bramucci E, Mannucci PM. Tissuefactor antigen and activity in human coronary atherosclerotic plaques. Lancet 1997; 349:769-771.

7. Camici GG, Steffel J, Akhmedov A, Schafer N, Baldinger J, Schulz $\cup$ et al. Dimethyl sulfoxide inhibits tissue factor expression, thrombus formation, and vascular smooth muscle cell activation: a potential treatment strategy for drug-eluting stents. Circulation 2006;114:1512-1521.

8. Steffel J, Akhmedov A, Greutert H, Luscher TF, Tanner FC. Histamine induces tissue factor expression: implications for acute coronary syndromes. Circulation 2005;112: $341-349$.

9. Steffel J, Arnet C, Akhmedov A, Iseli SM, Luscher TF, Tanner FC. Histamine differentially interacts with tumor necrosis factor-alpha and thrombin in endothelial tissue factor induction: the role of c-Jun $\mathrm{NH}_{2}$-terminal kinase. J Thromb Haemost 2006;4: $2452-2460$

10. Gasser SM, Cockell MM. The molecular biology of the SIR proteins. Gene 2001;279: $1-16$.

11. Lavu S, Boss O, Elliott PJ, Lambert PD. Sirtuins-novel therapeutic targets to treat age-associated diseases. Nat Rev Drug Discov 2008;7:841-853.

12. Imai S, Armstrong CM, Kaeberlein M, Guarente L. Transcriptional silencing and longevity protein Sir2 is an NAD-dependent histone deacetylase. Nature 2000;403: 795-800.

13. Motta MC, Divecha N, Lemieux M, Kamel C, Chen D, Gu W et al. Mammalian SIRT1 represses forkhead transcription factors. Cell 2004;116:551-563.

14. Luo J, Nikolaev AY, Imai S, Chen D, Su F, Shiloh A et al. Negative control of p53 by Sir2alpha promotes cell survival under stress. Cell 2001;107:137-148.

15. Picard F, Kurtev M, Chung N, Topark-Ngarm A, Senawong T, Machado De Oliveira R et al. Sirt1 promotes fat mobilization in white adipocytes by repressing PPAR-gamma. Nature 2004;429:771-776.

16. Mattagajasingh I, Kim CS, Naqvi A, Yamamori T, Hoffman TA, Jung SB et al. SIRT1 promotes endothelium-dependent vascular relaxation by activating endothelial nitric oxide synthase. Proc Natl Acad Sci USA 2007;104:14855-14860.

17. Yeung F, Hoberg JE, Ramsey CS, Keller MD, Jones DR, Frye RA et al. Modulation of NF-kappaB-dependent transcription and cell survival by the SIRT1 deacetylase. EMBO J 2004;23:2369-2380

18. Alcendor RR, Gao S, Zhai P, Zablocki D, Holle E, Yu X et al. Sirt1 regulates aging and resistance to oxidative stress in the heart. Circ Res 2007;100:1512-1521.

19. Ota H, Akishita M, Eto M, lijima K, Kaneki M, Ouchi Y. Sirt1 modulates premature senescence-like phenotype in human endothelial cells. I Mol Cell Cardiol 2007;43: $571-579$.

20. Lagouge M, Argmann C, Gerhart-Hines Z, Meziane H, Lerin C, Daussin F et al. Resveratrol improves mitochondrial function and protects against metabolic disease by activating SIRT1 and PGC-1alpha. Cell 2006;127:1109-1122.

21. Zhang QJ, Wang Z, Chen HZ, Zhou S, Zheng W, Liu G et al. Endothelium-specific overexpression of class III deacetylase SIRT1 decreases atherosclerosis in apolipoprotein E-deficient mice. Cardiovasc Res 2008;80:191-199.
22. Milne JC, Lambert PD, Schenk S, Carney DP, Smith JJ, Gagne DJ et al. Small molecule activators of SIRT1 as therapeutics for the treatment of type 2 diabetes. Nature 2007; 450:712-716.

23. Breitenstein A, Stampfli SF, Camici GG, Akhmedov A, Ha HR, Follath F et al. Amiodarone inhibits arterial thrombus formation and tissue factor translation. Arterioscler Thromb Vasc Biol 2008;28:2231-2238.

24. Buerki C, Rothgiesser KM, Valovka T, Owen HR, Rehrauer H, Fey M et al. Functional relevance of novel p300-mediated lysine 314 and 315 acetylation of RelA/p65. Nucleic Acids Res 2008;36:1665-1680.

25. Stein S, Schafer N, Breitenstein A, Besler C, Winnik S, Lohmann C et al. SIRT1 reduces endothelial activation without affecting vascular function in ApoE-/-mice. Aging (Albany NY) 2010;2:353-360.

26. Holy EW, Akhmedov A, Luscher TF, Tanner FC. Berberine, a natural lipid-lowering drug, exerts prothrombotic effects on vascular cells. J Mol Cell Cardiol 2009;46: 234-240.

27. Carpenter AE, Jones TR, Lamprecht MR, Clarke C, Kang IH, Friman O et al. CellProfiler: image analysis software for identifying and quantifying cell phenotypes. Genome Biol 2006;7:R100.

28. Araki T, Sasaki Y, Milbrandt J. Increased nuclear NAD biosynthesis and SIRT1 activation prevent axonal degeneration. Science 2004;305:1010-1013.

29. Fulco M, Schiltz RL, lezzi S, King MT, Zhao P, Kashiwaya $Y$ et al. Sir2 regulates skeletal muscle differentiation as a potential sensor of the redox state. Mol Cell 2003;12: 51-62.

30. Grubisha O, Smith BC, Denu JM. Small molecule regulation of Sir2 protein deacetylases. FEBS J 2005;272:4607-4616.

31. Chen LF, Greene WC. Shaping the nuclear action of NF-kappaB. Nat Rev Mol Cell Biol 2004;5:392-401.

32. Chen J, Zhou Y, Mueller-Steiner S, Chen LF, Kwon H, Yi S et al. SIRT1 protects against microglia-dependent amyloid-beta toxicity through inhibiting NF-kappaB signaling. J Biol Chem 2005;280:40364-40374.

33. Yang $Y$, Loscalzo J. Regulation of tissue factor expression in human microvascular endothelial cells by nitric oxide. Circulation 2000;101:2144-2148.

34. Yu JL, May L, Lhotak V, Shahrzad S, Shirasawa S, Weitz Jl et al. Oncogenic events regulate tissue factor expression in colorectal cancer cells: implications for tumor progression and angiogenesis. Blood 2005;105:1734-1741.

35. Nemerson Y. Tissue factor and hemostasis. Blood 1988;71:1-8.

36. Day SM, Reeve JL, Pedersen B, Farris DM, Myers DD, Im M et al. Macrovascular thrombosis is driven by tissue factor derived primarily from the blood vessel wall. Blood 2005;105:192-198.

37. Pedersen B, Holscher T, Sato Y, Pawlinski R, Mackman N. A balance between tissue factor and tissue factor pathway inhibitor is required for embryonic development and hemostasis in adult mice. Blood 2005;105:2777-2782.

38. Libby P, Ridker PM, Maseri A. Inflammation and atherosclerosis. Circulation 2002;105: 1135-1143.

39. Reilly MP, Rohatgi A, McMahon K, Wolfe ML, Pinto SC, Rhodes T et al. Plasma cytokines, metabolic syndrome, and atherosclerosis in humans. J Investig Med 2007;55: 26-35.

40. Annex BH, Denning SM, Channon KM, Sketch MH Jr., Stack RS, Morrissey JH et al. Differential expression of tissue factor protein in directional atherectomy specimens from patients with stable and unstable coronary syndromes. Circulation 1995;91: 619-622.

41. Banks AS, Kon N, Knight C, Matsumoto M, Gutierrez-Juarez R, Rossetti L et al. SirT1 gain of function increases energy efficiency and prevents diabetes in mice. Cell Metab 2008;8:333-341.

42. Lee JH, Song MY, Song EK, Kim EK, Sung Moon W, Han MK et al. Overexpression of SIRT1 protects pancreatic \{beta\}-cells against cytokine toxicity through suppressing NF-\{kappa\}B signaling pathway. Diabetes 2009;58:344-351.

43. Guarente L, Picard F. Calorie restriction-the SIR2 connection. Cell 2005;120: $473-482$.

44. Fontana L, Klein S. Aging, adiposity, and calorie restriction. JAMA 2007;297:986-994.

45. Diamant M, Nieuwland R, Pablo RF, Sturk A, Smit JW, Radder JK. Elevated numbers of tissue-factor exposing microparticles correlate with components of the metabolic syndrome in uncomplicated type 2 diabetes mellitus. Circulation 2002;106:2442-2447.

46. Lim HS, Blann AD, Lip GY. Soluble CD40 ligand, soluble P-selectin, interleukin-6, and tissue factor in diabetes mellitus: relationships to cardiovascular disease and risk factor intervention. Circulation 2004;109:2524-2528.

47. Felmeden DC, Spencer CG, Chung NA, Belgore FM, Blann AD, Beevers DG et al. Relation of thrombogenesis in systemic hypertension to angiogenesis and endothelial damage/dysfunction (a substudy of the Anglo-Scandinavian Cardiac Outcomes Trial [ASCOT]). Am J Cardiol 2003;92:400-405. 